\title{
Am I (un)safe here? Chemotherapy patients' perspectives towards engaging in their safety
}

\author{
David L B Schwappach, ${ }^{1,2}$ Martin Wernli ${ }^{3}$
}

${ }^{1}$ Swiss Patient Safety Foundation, Zürich, Switzerland

Institute of Social and Preventive Medicine (ISPM), University of Bern, Switzerland ${ }^{3}$ Division of

Haematology/Oncology, Kantonsspital Aarau AG. 5001 Aarau, Switzerland

\section{Correspondence to} Dr David L B Schwappach, Swiss Patient Safety Foundation, Asylstr. 77, 8032 Zürich, Switzerland; schwappach@ patientensicherheit.ch

Accepted 20 June 2009 Published Online First 27 April 2010

\begin{abstract}
Objectives To assess chemotherapy patients' perceptions of safety and their attitudes towards participating in error-prevention strategies.

Design Semistructured interviews were conducted with 30 chemotherapy patients at baseline. Follow-up interviews were conducted 9 weeks later.

Setting A community hospital in Switzerland.

Results Though patients had experienced errors in their care, they were only moderately worried about safety, risk of errors and the potential for harm. At follow-up, worries about safety had increased, and patients reported a higher degree of vigilance. Participants unequivocally agreed that patients can make contributions to their safety, and many patients were prepared to get involved. Patients described engaging in their safety as a learning process and highlighted the importance of being proactive, asking questions and communicating any observations of deviations from routines. Commonly recommended error-prevention strategies were rated as highly effective. Instruction by nurses was central for patients, but the underlying reasons varied. There was no indication that patients perceive participation in safety actions as eroding trust in their providers.

Conclusions Patients are prepared to engage in their safety, but the encouragement by staff is vital. Involvement of patients with cancer in medication administration safety needs to acknowledge patients' conceptions of these activities and their varying abilities at different stages in the treatment process.
\end{abstract}

\section{INTRODUCTION}

Adverse event studies report that errors in chemotherapy occur frequently. ${ }^{1-3}$ In a Swiss study, $15 \%$ of handwritten chemotherapy prescriptions involved errors, of which $19 \%$ were major. ${ }^{4}$ Common errors include under- and overdosing, schedule and timing errors, and other incidents such as infusion-rate errors. The diffusion of oral and infusion chemotherapy to the outpatient setting is likely to introduce additional hazards. ${ }^{5}$ In a recent analysis of outpatient cancer treatments, $7.1 \%$ of adult and $18.8 \%$ of paediatric visits were associated with a medication error. ${ }^{6}$ More than half of all errors occurred in the administration of drugs-for example, confusion over two sets of orders. There is also evidence that patients frequently observe, report and intercept errors. ${ }^{7-9}$ For example, patients often recognise when the wrong drugs or incorrect doses of the right drug are being given, or that devices such as infusion pumps malfunction. ${ }^{10} 11$ Unruh and Pratt report how chemotherapy patients, who usually have intense, recurring episodes of care, identify errors by checking concordance of prior experiences and information, more or less randomly obtained, to formulate rules and to check reality against these rules. $^{12}$

It seems plausible to tap into and expand this potential and support chemotherapy patients in the detection and prevention of errors. The 'Speak Up' initiative of the Joint Commission targeting the general patient population recommends to patients that 'if you are given an IV [intravenous], ask the nurse how long it should take for the liquid to run out. Tell the nurse if it doesn't seem to be dripping right. ${ }^{13}$ The 'You can' campaign at the Dana-Farber Cancer Institute asks patients to 'Check. Ask. Notify.' ${ }^{14}$ Some US cancer centres provide patients with a card that lists their medications and that they can update as they receive treatment at different sites. ${ }^{15}$ Despite the proliferation of these programmes, little is known about chemotherapy patients' attitudes towards engaging in their safety, and available evidence is inconclusive. Davis et al present several theoretical arguments derived from the general shared decisionmaking literature and discuss these relative to the unique situation of patients with cancer. ${ }^{16}$ In the present study, semistructured interviews with patients currently receiving chemotherapy were conducted to assess their experiences with, and worries about, errors in chemotherapy administration, their general perceptions of chemotherapy safety and safety practices, their attitudes towards involvements in safety and participation in specific prevention strategies.

\section{METHODS}

The study took place in a large Swiss community hospital. This hospital serves a population of roughly 500000 inhabitants from both rural and urban areas in Switzerland. Chemotherapy was provided by a large outpatient infusion unit and on inpatient wards of several departments (eg, internal medicine, surgery). This study was designed as part of a larger study on patient safety in chemotherapy and was preceded by focus-group discussions with oncology nurses involved in chemotherapy administration. ${ }^{17}$

\section{Participants}

Patients were consecutively informed about the study and asked for participation by an attending physician at their regular visit. Patients who were considered to be too ill had major communication difficulties or did not provide written informed consent were excluded. We were not able to consistently document exclusion of patients for practical reasons. Attending physicians reported that they consecutively approached roughly $95 \%$ of 
their chemotherapy patients, and approximately 20\% declined participation. There were two drop-outs after study inclusion but before the baseline interview (one patient death, one withdrawal due to health deterioration), and none lost to follow-up.

\section{Interviews}

We hypothesised that patients carry with them important and valuable experiences and observations but that these would not necessarily be straightforwardly accessible to them. Rather, we expected that interview participation would sharpen their observations and allow them to better interpret their clinical environment-for example, safety practices of nurses. To gain insight into these experiences, follow-up interviews were conducted approximately 9 weeks after the initial meeting. The questionnaire guides for the two interviews were developed based on a review of the literature and on clinical experience, and were pilot-tested. ${ }^{18} 19$

\section{Data collection and analysis}

The questionnaire included the open-ended and closed-ended questions listed in table 1.

Interviews were administered by a trained and experienced research assistant, audio-recorded and transcribed verbatim. The interviews lasted an average of $54 \mathrm{~min}$ (range 40 to 87) at baseline and $26 \mathrm{~min}$ (range 18 to 38 ) at follow-up. Responses to the closed questions were analysed quantitatively. A content-analysis framework was applied to the open questions. Texts were divided into units of meaning and coded, grouped and condensed into categories. ${ }^{20}$ Emergent themes and recurring ideas were identified and classified in terms of arising concepts. Analytical categories were abstracted. ${ }^{21}$ Two researchers independently analysed the transcripts in an iterative process. Areas of disagreement were discussed in feedback loops to increase validity. ${ }^{22}{ }^{23}$ Within a feedback loop, categories were revised, reduced to main categories and checked in respect to their reliability. ${ }^{24} \mathrm{New}$ codes were added as additional themes emerged, and some codes were eliminated. The finalised code structure was then applied to all transcripts. $^{21} 25$ Saturation, that is, the point at which no new information was observed in the data, was achieved after 26 initial and 19 follow-up interviews. As reported by others, the range of thematic discovery and the vast majority of code revisions had occurred much earlier. ${ }^{26}$ Data were organised in themes, and representative quotes were selected.

\section{RESULTS}

Demographic and clinical characteristics of the participants are provided in table 2 .

Table 1 Themes addressed in the interview

\begin{tabular}{|c|c|}
\hline $\begin{array}{l}\text { Themes addressed in } \\
\text { closed-ended questions }\end{array}$ & $\begin{array}{l}\text { Themes addressed in } \\
\text { open-ended questions }\end{array}$ \\
\hline Demographic and clinical details & Experience of error \\
\hline Experience of error & Perceptions of risk of error and harm \\
\hline Worry about errors & Experience of engaging in safety \\
\hline Perceived risk of error & $\begin{array}{l}\text { Perception of chemotherapy } \\
\text { administration and safety practices }\end{array}$ \\
\hline $\begin{array}{l}\text { Patients' contribution to prevention } \\
\text { of errors }\end{array}$ & $\begin{array}{l}\text { Attitudes towards patients' engagement } \\
\text { in safety }\end{array}$ \\
\hline Feelings of overstrain & Feelings of overstrain \\
\hline $\begin{array}{l}\text { Attitudes towards engaging in their } \\
\text { safety }\end{array}$ & Patients' strategies to prevent errors \\
\hline $\begin{array}{l}\text { Self-efficacy in protecting themselves } \\
\text { from error as compared to other } \\
\text { patients }\end{array}$ & $\begin{array}{l}\text { Expectations and interpretations of the } \\
\text { presented error-prevention strategies }\end{array}$ \\
\hline $\begin{array}{l}\text { Ratings of effectiveness and likelihood } \\
\text { of taking action for different error- } \\
\text { prevention strategies }\end{array}$ & Relationship to nurses, in particular trust \\
\hline
\end{tabular}

Table 2 Characteristics of study participants $(n=30)$

\begin{tabular}{lc}
\hline Characteristic & No of participants (\%) \\
\hline Age, years & \\
$<45$ & $4(13)$ \\
$45-54$ & $10(33)$ \\
$55-64$ & $7(23)$ \\
$65-75$ & $8(27)$ \\
$\geq 75$ & $1(3)$ \\
Female gender & $16(53)$ \\
Education & \\
Primary & $7(23)$ \\
Secondary & $12(40)$ \\
Tertiary & $11(37)$ \\
Type of cancer & \\
Blood, blood-building organ & $13(43)$ \\
Breast & $5(17)$ \\
Colon/rectum & $4(13)$ \\
Pancreas & $3(10)$ \\
Prostate & $3(10)$ \\
Other & $2(7)$ \\
Months since cancer diagnosis & \\
$<6$ & $10(33)$ \\
$7-12$ & $6(20)$ \\
13-24 & $4(13)$ \\
$\geq 36$ & $10(33)$ \\
Antineoplastic medication & \\
Chemotherapy & $25(83)$ \\
Antibody/immunotherapy & $3(10)$ \\
Combination & $2(7)$ \\
Application of therapy & \\
Infusion & $25(83)$ \\
Oral & $3(1)$ \\
Combination (oral/intravenous) & \\
\hline & \\
&
\end{tabular}

Fourteen patients reported experiences with errors and adverse events in chemotherapy. The term 'adverse event' was used in interviews by patients for unintended incidents with actual or potential harm for which the distinction between error and complication was not possible. Most of these reports related to wrong or omitted medications and doses, in particular comedications, painful/problematic implantation or puncturing of portacath systems, and failures in communicating medication adjustments between doctors and nurses:

When they set up the intravenous line last time, they hit something wrong accidentally. It hurt like hell, and they were getting nervous...but nobody would address this towards me. It still hurts today.

There were also a number of reports in which errors were intercepted by patients:

When I stayed at the surgical unit, they gave me the wrong tablets. I recognised that because they had different colour and texture.'

Once, the nurse came in with only one intravenous bag. I asked him why I should only have one. I always had two bags, you know. He left the room.... and came back only after a minute, smiling, and with the second bag.

Despite these experiences, patients reported feeling safe and were relatively unworried about errors (table 3 ). Neither the quantitative ratings of worry $\left(\chi^{2}\right.$ test statistic $\left.=0.0335, p=0.855\right)$ nor qualitative descriptions of perceived safety were associated with the experience of error. However, patients who had not experienced errors had a more narrow understanding and 
Table 3 Worries about chemotherapy error and risk perception

\begin{tabular}{lcc}
\hline Variable & Percentage of participants \\
\hline Level of worry about errors in chemotherapy & Follow-up \\
& Baseline & 10 \\
Very worried & 0 & 40 \\
Somewhat worried & 20 & 50 \\
Not at all worried & 80 & \\
Perceived risk of error in chemotherapy as compared with error in myocardial \\
infarction treatment \\
Higher/much higher \\
Similar \\
Lower/much lower & 0 & \\
Perceived risk of error in chemotherapy as compared with error in hip-fracture \\
treatment \\
Higher/much higher \\
Similar \\
Lower/much lower & 4 \\
\end{tabular}

perception of safety and associated treatment errors with harm. Participants who had experienced an error referenced a broader range of errors (eg, communication errors) and intercepted errors and acknowledged their care givers' safety practices.

Patients estimated that the prevalence of errors in chemotherapy was lower than that to other treatments. Some patients referred to the safety practices that they had observed, occasionally contrasting these experiences to earlier treatments at other centres:

They double-check everything here. They have strict rules. I feel safe here... errors can happen, but they do everything to avoid them. When I went to the (institution) earlier I was truly worried...they have a chaos there. I'm sure a lot of mistakes happen there.

However, most patients' degree of worry, while minor, seemed to stem from the perception that there was little risk of error in chemotherapy administration itself and only minor harm was associated with errors rather than from their observations of safety practices (table 3 ):

They fill it in these bags at the pharmacy, and hang the bag on. What could go wrong?'

With myocardial infarction, time is really a matter. But with chemo, in case you get too much of the drug, they have always opportunities to work against harm. There is always some

....antidote.... I don't think that it is such a sensitive issue. I know,

it is toxic, but...I don't believe that small deviations really matter.

At the follow-up interview, patients' worries had increased significantly (Wilcoxon matched-pairs signed-rank test, $z=2.634$, $\mathrm{p}=0.0084$ ). Most participants reported elevated attentiveness towards the drug administration process. For example, patients more sensitively and closely followed the drug-checking procedures with the administering nurse:

It's not that I'm watching with a critical eye now. It is more...I would call it 'vigilant.' Yes, I guess I'm more vigilant...really watchful now.

Many said that they learnt through the initial interview which issues to monitor and how to respond. Few reported situations of error in which they had intervened (eg, one patient detected a blood test tube labelled with another patient's name).

At both interviews, patients unequivocally agreed that patients can help to prevent errors. One stated,

Very important. You need to think actively.
Most regarded communication issues as important strategies in preventing errors and said that being proactive, asking questions, communicating with staff, reporting symptoms to clinicians and communicating any observations of deviations from routines are contributions that patients can make, depending on their physical and psychological well-being:

I inspect everything. And I would ask. You should always ask. There is no harm in asking. If something is unclear, or doesn't seem to be right, or if you didn't understand you have to ask. You cannot simply shift responsibility.

While patients were prepared to engage in error prevention, they were also well aware of their limited capabilities and opportunities to detect errors. Some mentioned that it takes courage to engage in safety:

I can read the labels on the bags, and I can check everything what they do here (in the chemotherapy administration room), but...who knows what they do in the pharmacy?

I'm not a chemist. I have to trust them. As a patient, you have only limited knowledge.

When asked to compare their own ability to that of other patients in protecting themselves from errors in chemotherapy, $46 \%$ (40\% at follow-up) thought that they had better capabilities compared with other patients, and 54\% (60\% follow-up) expected to perform similar as other patients. None responded as having a lesser capability. A number of patients explained that, to them, participation in safety was a learning process. It starts with very limited knowledge and feelings of strain at the beginning of therapy and proceeds, with additional experiences of chemotherapy administration, to some level of 'expert status':

Not at the beginning. It's just too much then...But after a while, you know how things are running. You know the names of the drugs and how they do it (administering the drugs) and I'm sure I would realise if anything was different from that. It's ... routine, after a while.

Participants were then presented with a number of administration error-prevention strategies commonly recommended to patients and asked to rate their effectiveness, report whether they had used these strategies, what their experiences were and whether they would utilise the suggestions. Most of the actions were judged to be effective (shown in table 4), and several patients discussed occurrences in which they already had or would employ the preventive strategies and/or what they thought about them:

Yes, I'm checking my pills already. I always compare against the chemotherapy schedule. I asked for a copy of that.

We (patient and nurse) always check intravenous bags together This is a good thing. If there is something I can contribute in my care-this is good. I feel active and part of it, part of the process. And that's a good feeling!

If they would also explain to me how it should function, yes. I do not know how it looks if the intravenous is dripping right, or whether the line is connected appropriately. I do not know yet.

There was little variance in the likelihood of taking action across the different behaviours. In the interviews, it became clear that patients anticipated participating in safety actions if only nurses instructed them to. However, the interpretations of the causes underlying the hypothetical instruction varied. Many 
Table 4 Ratings of effectiveness and likelihood of taking action if instructed to by oncology nurses

\begin{tabular}{|c|c|c|}
\hline Error-prevention strategy & $\begin{array}{l}\text { Mean effectiveness } \\
\text { rating* }\end{array}$ & $\begin{array}{l}\text { Mean likelihood of taking action if } \\
\text { instructed to by oncology nurses } \dagger\end{array}$ \\
\hline $\begin{array}{l}\text { Pay attention to the appearance of tablets or } \\
\text { infusions-for example, their colour and } \\
\text { shape, and notify staff if they are unusual }\end{array}$ & 1.23 & 4.73 \\
\hline Pay attention to the number of drugs & 1.20 & 4.73 \\
\hline Pay attention to the duration of infusions & 1.97 & 4.50 \\
\hline $\begin{array}{l}\text { Pay attention to the correct functioning of } \\
\text { equipment-for example if the intravenous is } \\
\text { dripping slower or faster as usual or if the line } \\
\text { is disconnected }\end{array}$ & 1.50 & 4.40 \\
\hline $\begin{array}{l}\text { Ask the nurse when administering drugs to } \\
\text { check whether they are really meant to be for } \\
\text { you-for example to check the labels on } \\
\text { intravenous bags with your name }\end{array}$ & 1.27 & 4.57 \\
\hline $\begin{array}{l}\text { Ask staff to interrupt an intervention and } \\
\text { check back if you have any doubts that } \\
\text { everything is fine }\end{array}$ & 1.17 & 4.73 \\
\hline $\begin{array}{l}\text { Ask the nurse or doctor to read out loud the } \\
\text { drugs label before administering the drug }\end{array}$ & 1.63 & 4.40 \\
\hline $\begin{array}{l}\text { Ask nurses and doctors whether they had } \\
\text { washed their hands before touching you }\end{array}$ & 1.47 & 4.10 \\
\hline $\begin{array}{l}\text { Inform nurses or doctors whenever you } \\
\text { experience any symptoms - for example pain } \\
\text { at the injection site }\end{array}$ & 1.13 & 4.90 \\
\hline $\begin{array}{l}\text { Pay attention that treatment days follow the } \\
\text { regular interval or schedule-for example, } \\
\text { weekly on the same day of the week }\end{array}$ & 1.57 & 4.60 \\
\hline
\end{tabular}

patients perceived nurses' instructions as signalling the importance of the behaviour and the patient's role in ensuring safe administration, but others argued that they aimed to support nurses in their work:

If they asked me to, then I would. Because... It must be important then, I guess.

They would really challenge me with that (laugher). But, I would have to do it then.

If they read the labels out loud, the patient has some control. They need to concentrate then, more as if they checked by themselves.

I guess it increases their (the nurses') safety as well. It's like an additional control for them. I guess they appreciate that.

Though rare, some patients rejected active participation as described above, mainly because they felt that this was not their role:

No. That is their business. I have enough to watch for. No, I really do not want to look after their errors.

I would not (check whether the intravenous line is dripping right). There must be something left to do for them, too (laughter). I'm not here to do their job.

At the follow-up interview, several patients reported having implemented the potential safety behaviours discussed at baseline. Patients overwhelmingly reported that their participation in error prevention would not negatively affect relationships with their care givers or erode trust. No patients experienced unintended consequences-for example, conflict situations. Rather, engaging in safety was perceived as strengthening the relationship with nurses. A patient who had implemented some of the safety behaviours after the initial interview reported:

Now, when I check the drugs, it is a good feeling of trust. Because, now I know that I can have trust, that my trust is justified. Before that it was simply 'blind faith.'

\section{DISCUSSION}

Despite the widespread experiences of patients in the present study that errors in chemotherapy do happen, and despite the same patients' sensitive identification of safety practices in chemotherapy administration, they were only moderately worried about safety and perceived the risk of error as lower compared with other treatments. The qualitative data revealed that trust in the effectiveness of safety practices in intercepting errors and in preventing or ameliorating harm and little awareness towards chemotherapies' potential to cause harm were prevalent among patients. These perceptions seem to accumulate in perceptions of risk and degree of worry. Compared with actual figures, patients tended to underestimate the risk of error and potential for harm. The incidence of errors in cancer treatment has been shown to be as high as with other treatments. ${ }^{16}$ Intravenous anticancer drugs are among the most frequently involved in errors. ${ }^{27} 28$ For example, the rates of clinically significant medication order errors per 100 patient days were 0.80 in haemato-oncology, 0.11 in internal medicine and 0.34 in surgery. ${ }^{29}$ The relative frequency of errors with the potential to cause harm is even higher than with other treatments. ${ }^{1}$ Walsh et al report that $61 \%$ of medication errors in adult patients had the potential to injure, and $12 \%$ resulted in injury. ${ }^{6}$ 
Patients' low degree of worry is surprising given the widespread conception of chemotherapy as being highly toxic and hazardous, and the cultural meanings assigned to this cancer treatment. ${ }^{30}$ At the follow-up interviews, concerns about safety had increased, and patients reported a higher degree of vigilance and adopted some of the behaviours described to them at baseline. As recent research suggests, information about errorprevention strategies may have increased self-efficacy and worry, both of which affect preventive efforts and intentions to take precautionary actions. ${ }^{31}{ }^{32}$ Indeed, worry seems to be a better predictor than risk perceptions. However, this poses ethical concerns, as worry may counteract other important dimensions of the patient-provider encounter, such as trust and accountability. However, worry may be acceptable if the perceived risk of serious harm is low and/or perceived preventability of errors and effectiveness of protective behaviours are high. ${ }^{33}$ Finally, a certain degree of worry seems a reasonable response given the incidence of errors, and it would also be questionable to lure patients into an artificial sense of safety. It is also of relevance whether feelings of worry relate to the inherent risk of error or to trust in providers' error-prevention and management practices. In the present study, there was no indication that patients perceive participation in safety as bearing the risk of eroding trust to their providers. This mirrors results of focus-group discussions conducted with oncology nurses who reported that involving patients in safety management would strengthen the relationship to patients, rather than undermine it. ${ }^{17}$

Participants unequivocally agreed that patients can make contributions to their safety, and most were willing to get involved. Neither worry nor willingness to engage in safety seemed to be affected by prior error experiences, except that patients who reported errors shared a broader understanding of potential errors and a more precise understanding of how to participate in error-prevention strategies. Studies conducted in general population convenience samples have also shown no association between experience of error and worry and selfefficacy. ${ }^{31} 32$ It is interesting to note that patients rated their self-efficacy higher than with other patients and described their capabilities for engaging in their own safety as a learning process. This finding may be explained by the relatively long time interval since cancer diagnosis in our sample. It seems crucial that involvement of patients with cancer in medication administration safety should take into consideration patients' varying levels of abilities at different stages in the treatment process. In addition, these results suggest that patient involvement in safety may be categorically different in patients with single acute episodes of care. Chemotherapy patients experience a care process in which they gather knowledge and skills, and continuous relationships with providers in which education of patients in general (eg, relating to symptom management) and feedback typically play a major role.

The main limitations of this study are the small sample size and the restriction to one treatment site. As the aim of this study was to identify major themes, generalisability is clearly restricted. However, the distribution of gender and educational attainment within our sample-socio-demographic characteristics that are likely to affect attitudes towards and engagement in safety-related behaviours-reflects that of the general Swiss population above 35 years of age. ${ }^{34}$ Our sample represents patients undergoing continuing treatment. We chose this group of patients to minimise hypothetical bias that may explain observed differences between patients' general attitudes towards involvement in error-prevention strategies and their actual behaviour. ${ }^{35}$ Again, our findings may not apply to patients with non-recurring episodes of care.

The error-prevention strategies discussed were perceived as being highly effective, though some patients were well aware of the limited potential that these actions have in detection and interception of errors. Patients referred to processes preceding drug administration, in particular, the physician's prescribing drugs and the pharmacy's preparation and dispensing of drugs. These statements often carried connotations of frustration and disillusion. Such concerns, potentially accompanied by descriptions of professional activities to prevent errors, need to be addressed by campaigns that aim to motivate patients to engage in their safety.

Our study also highlights the crucial role of oncology nurses in engaging patients. As in other studies, we found that patients anticipated participating in a variety of safety actions under the condition they had been instructed by clinical staff. ${ }^{36}$ The limited variance across different behaviours and discussions with patients showed that patients felt strongly committed to following their nurses' instructions. However, their reasons varied markedly, something that we would not have easily detected within the quantitative data. While most patients understood the hypothetical instructions to follow prevention behaviours as underlining the importance of the action and joint efforts to increase safety, others referenced to 'being compliant,' to 'relieve nurses,' or simply to 'do what was being expected from them.' Discussions with oncology nurses indeed showed that nurses sensitively choose among a set of strategies and patterns of language to engage patients and switch between participatory and authoritative models of education. ${ }^{17}$ Professionals involved in engaging patients in their safety, in particular patients who develop close relations with their care givers, need to be aware of these different concepts and recognise that not all patients will want to or be able to participate, and that this will change over time and with context. If these caveats are accounted for, the involvement of patients in safety can be a promising strategy and an opportunity to strengthen trust and teambuilding.

Acknowledgements The authors greatly appreciate the patients' participation in the interviews. The valuable work of $\mathrm{J}$ Ammann in conducting the interviews is highly acknowledged. We also thank the medical staff of the oncology/haematology unit of the Kantonsspital Aarau for recruiting patients and for their support in organisational matters. Finally, the authors are grateful for the expertise and support of C Carlson in data analysis.

Funding Financial support for this study was provided by a research grant from oncosuisse (OCS-02109-08-2007).

\section{Competing interests None.}

Ethics approval Ethics approval was provided by the local Ethics Committee of the Canton of Aarau (ref. 2008/035).

Provenance and peer review Not commissioned; externally peer reviewed.

\section{REFERENCES}

1. Gandhi TK, Bartel SB, Shulman LN, et al. Medication safety in the ambulatory chemotherapy setting. Cancer 2005;104:2477-83.

2. Markert A, Thierry V, Kleber $\mathrm{M}$, et al. Chemotherapy safety and severe adverse events in cancer patients: strategies to efficiently avoid chemotherapy errors in inand outpatient treatment. Int J Cancer 2009;124:722-8.

3. Rinke ML, Shore AD, Morlock $L$, et al. Characteristics of pediatric chemotherapy medication errors in a national error reporting database. Cancer 2007;110:186-95.

4. Voeffray M, Pannatier A, Stupp R, et al. Effect of computerisation on the quality and safety of chemotherapy prescription. Qual Saf Health Care 2006;15:418-21.

5. Taylor JA, Winter L, Geyer LJ, et al. Oral outpatient chemotherapy medication errors in children with acute lymphoblastic leukemia. Cancer 2006;107:1400-6.

6. Walsh KE, Dodd KS, Seetharaman K, et al. Medication errors among adults and children with cancer in the outpatient setting. J Clin Oncol 2008;27:891-6. 
7. Schwappach DL. 'Against the silence': development and first results of a patient survey to assess experiences of safety-related events in hospital. BMC Health Serv Res 2008;8:59.

8. Weissman JS, Schneider EC, Weingart SN, et al. Comparing patient-reported hospital adverse events with medical record review: do patients know something that hospitals do not? Ann Intern Med 2008:149:100-8.

9. Weingart SN, Price J, Duncombe D, et al. Patient-reported safety and quality of care in outpatient oncology. Jt Comm J Qual Patient Saf 2007;33:83-94.

10. Schulmeister L. Chemotherapy medication errors: descriptions, severity, and contributing factors. Oncol Nurs Forum 1999;26:1033-42.

11. Muller T. Typical medication errors in oncology: analysis and prevention strategies Onkologie 2003;26:539-44.

12. Unruh KT, Pratt W. Patients as actors: the patient's role in detecting, preventing and recovering from medical errors. Int J Med Inf 2007:76(Suppl 1):S236-44.

13. Joint Commission. Speak up initiatives. 2008. http://www.jointcommission.org/ PatientSafety/SpeakUp/ (accessed 9 Sep 2008)

14. Weingart SN, Simchowitz B, Kahlert Eng T, et al. The You CAN Campaign: teamwork training for patients and families in ambulatory oncology. Jt Comm J Qual Patient Saf 2009;35:63-71.

15. Finkelstein JB. E-prescribing first step to improved safety. J Natl Cancer Inst 2006;98:1763-5.

16. Davis RE, Jacklin R, Sevdalis N, et al. Patient involvement in patient safety: what factors influence patient participation and engagement? Health Expect 2007; 10:259-67.

17. Schwappach DLB, Hochreutener M-A, Wernli M. Oncology nurses' perceptions about involving patients in the prevention of chemotherapy administration errors. Oncol Nurs Forum 2010;37:E84-91.

18. Schwappach DLB. Engaging patients as vigilant partners in safety. A systematic review. Med Care Res Rev 2010;67:119-48.

19. Schwappach DLB, Wernli M. Medication errors in chemotherapy: Incidence, types, and involvement of patients in prevention. A review of the literature. Eur $\mathrm{J}$ Cancer Care (Engl). Published Online First: 25 August 2009. doi: 10.1111/j.1365-2354. 2009.01127.x.

20. Elo S, Kyngas $H$. The qualitative content analysis process. J Adv Nurs 2008;62:107-15

21. Sandelowski M. Whatever happened to qualitative description? Res Nurs Health 2000:23:334-40.
22. Graneheim UH, Lundman B. Qualitative content analysis in nursing research: concepts, procedures and measures to achieve trustworthiness. Nurse Educ Today 2004;24:105-12.

23. Vaughn S, Shay Schumm J, Sinagub J. Focus group interviews in education and psychology. Thousand Oaks: SAGE, 1996.

24. Mayring P. Qualitative content analysis. Forum qualitative social research. 2009. http://www.qualitative-research.net/fqs-texte/2-00/2-00mayring-e.htm laccessed 28 Apr 2009)

25. Bradley EH, Curry LA, Devers KJ. Qualitative data analysis for health services research: developing taxonomy, themes, and theory. Health Serv Res 2007:42:1758-72.

26. Guest G, Bunce A, Johnson L. How many interviews are enough?: An experiment with data saturation and variability. Field Methods 2006;18:59-82.

27. Winterstein AG, Johns TE, Rosenberg El, et al. Nature and causes of clinically significant medication errors in a tertiary care hospital. Am J Health Syst Pharm 2004;61:1908-16.

28. Ross LM, Wallace J, Paton JY. Medication errors in a paediatric teaching hospital in the UK: five years operational experience. Arch Dis Child 2000;83:492-7.

29. Lustig A. Medication error prevention by pharmacists-an Israeli solution. Pharm World Sci 2000;22:21-5.

30. Bell K. 'If it almost kills you that means it's working!' Cultural models of chemotherapy expressed in a cancer support group. Soc Sci Med 2009;68:169-76.

31. Hibbard JH, Peters E, Slovic P, et al. Can patients be part of the solution? Views on their role in preventing medical errors. Med Care Res Rev 2005;62:601-16.

32. Peters E, Slovic P, Hibbard JH, et al. Why worry? Worry, risk perceptions, and willingness to act to reduce medical errors. Health Psychol 2006;25:144-52.

33. Weinstein ND. Effects of personal experience on self-protective behavior. Psychol Bull 1989:105:31-50.

34. BFS (Swiss Federal Statistical Office). Swiss education statistic 2008 Neuchâtel: Federal Department of Home Affairs, BFS (Swiss Federal Statistical Office), 2009.

35. Waterman AD, Gallagher TH, Garbutt J, et al. Brief report: Hospitalized patients' attitudes about and participation in error prevention. J Gen Intern Med 2006;21:367-70.

36. Davis RE, Koutantji M, Vincent CA. How willing are patients to question healthcare staff on issues related to the quality and safety of their healthcare? An exploratory study. Qual Saf Health Care 2008;17:90-6. 